Engineering and Computational Mechanics Volume 165 Issue EM2

Draw-down and run-up of tsunami waves on sloping beaches

Klettner, Balasubramanian, Hunt et al.
Proceedings of the Institution of Civil Engineers

Engineering and Computational Mechanics 165 June 2012 Issue EM2 Pages 119-129 http://dx.doi.org/10.1680/eacm. 10.00044

Paper 1000044

Received 08/12/2010 Accepted 21/09/2011

Keywords: mathematical modelling/models (physical)/weather

\title{
Draw-down and run-up of tsunami waves on sloping
}

beaches

Christian Klettner PhD

Post-doctoral Fellow, National University Hospital Singapore, Singapore Sridhar Balasubramanian PhD

Post-doctoral Research Scientist, Physics Division, Los Alamos National Laboratory, Los Alamos, NM, USA

Julian Hunt PhD

Emeritus Professor of Climate Modelling, University College London, London, UK; Visiting Professor, Arizona State University, Tempe, AZ, USA; Visiting Professor, J. M. Burgers Centre, University of Technology, Delft, the Netherlands
Harindra Fernando PhD

Professor of Engineering and Geosciences, University of Notre Dame, Notre Dame, IN, USA

Sergey Voropayev PhD

Professor, University of Notre Dame, Notre Dame, IN, USA; Chief Scientist, Institute of Oceanology, Russian Academy of Sciences, Moscow, Russia

Ian Eames

Reader of Fluid Mechanics, University College London, London, UK

The dynamics of waves and their interaction with a beach depends on whether the leading wave component is elevated or depressed. These differences are explained in this paper using a hydraulic model and the principle of conservation of impulse. Laboratory experiments of depression waves, conducted using a novel wavemaker, are compared with model predictions. Over a sloping beach, these waves have a nearly constant V-shaped depression trailed by a growing $\Lambda$-shaped positive wave. The shoreline recedes over a significant distance, caused by shoreward water being drawn into the V-shaped depression. When the trailing $\Lambda$-shaped positive wave breaks, an energetic hydraulic bore develops and moves up the beach. The hydraulic model leads to general formulae for wave slopes, draw-down and run-up. The run-up of negative waves can be larger or smaller than that of positive waves, depending on the wave amplitude and beach parameters. The predictions are compared with results from photographs of depression waves taken during the 2004 Sumatra tsunami. Similar phenomena occurred in Japan in 2011. By incorporating up/down amplitude data in new tsunami warning systems, the properties of tsunamis on beaches could be estimated in real time using the present work, thus improving emergency response strategies. In future, the damage associated with tsunami waves, depending on coastal parameters, could increase with rising sea levels, erosion and destruction of coral reefs, and the loss of Arctic sea-ice.

\section{Introduction}

Sometimes, long isolated tsunami waves that travel towards beaches with depressed rather than elevated water surfaces are formed; this was indeed the case following the 2004 South East Asian earthquake. The behaviour of these depressed waves is quite different and has not previously been studied in detail. Groups of waves with positive and negative amplitudes also behave differently (Carrier et al., 2003). Although depressed long waves, as generated by the Sumatra earthquake in 2004 for instance, cause great damage on beaches and further inland, they have not been studied as extensively as positive waves (Fernando et al., 2008a). However their importance has been highlighted in the literature through analytical studies (Tadepalli and Synolakis, 1994), extensive field data (Soloviev and Mazova, 1994) and experimental work (Kobayashi and Lawrence, 2004).

The first objective of this paper is to present a new weakly nonlinear hydraulic model to calculate the amplification of a depressed long wave as it approaches a beach. Since such tsunamis are not wave packets, wave analysis is not appropriate (Carrier et al., 2003; Tadepalli and Synolakis, 1996). Typically, this wave form develops into a constant V-shape trailed by a (growing) $\Lambda$-shaped positive wave. Local non-linear dynamics explain the transformation of the wave as the depressed V-shaped front causes the shoreline to recede. The growing $\Lambda$-shaped rear of the wave grows and a bore forms. The principle of conservation of momentum leads to dimensional scaling in terms of the amplitude and wavelength of the wave movements before and after the wave breaks, particularly its most significant features such as the maximum retreat of the shoreline, the peak velocity and amplitude of the bore and the maximum displacement of the bore up the beach.

The second aim of this paper is to test the concepts and scaling results for negative and positive isolated waves using a laboratory wave tank and to compare the results with data on full-scale tsunamis. A mathematical model describing the wave before and 
after it breaks is presented in Section 2. Section 3 details the laboratory experiments. The experimental results, the model predictions and full-scale tsunami observations are compared in Section 4 and discussed in Section 5. Conclusions are presented in Section 6.

\section{Mathematical model}

The model considers how long waves with initially small amplitude $a_{0}$ and length $L_{0}$ travel on an undisturbed water surface whose depth $h(x)$ is constant $\left(=h_{0}\right)$ for $x \leqslant 0$ and varies slowly with horizontal distance $x>0$ over an inclined bottom of slope

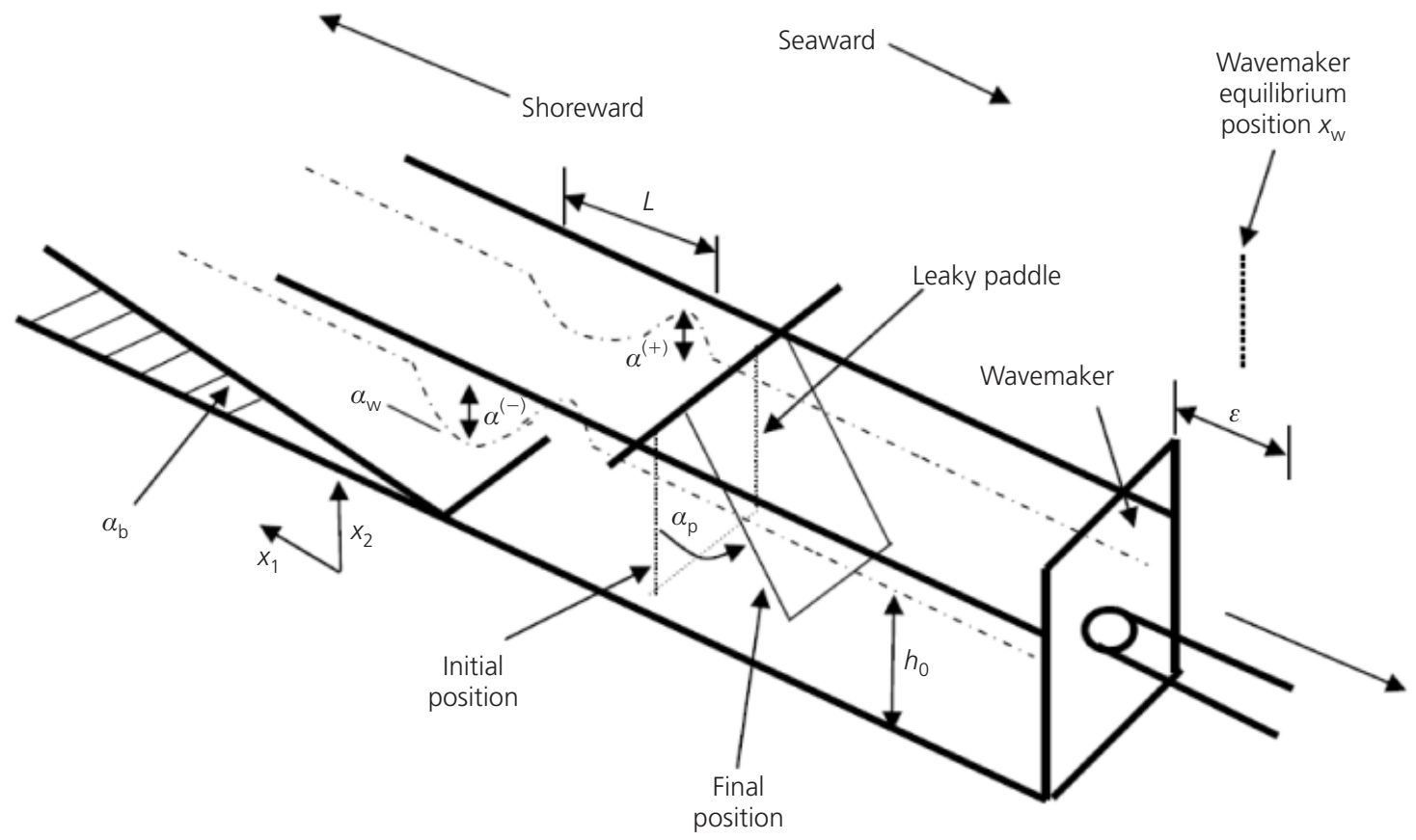

(a)

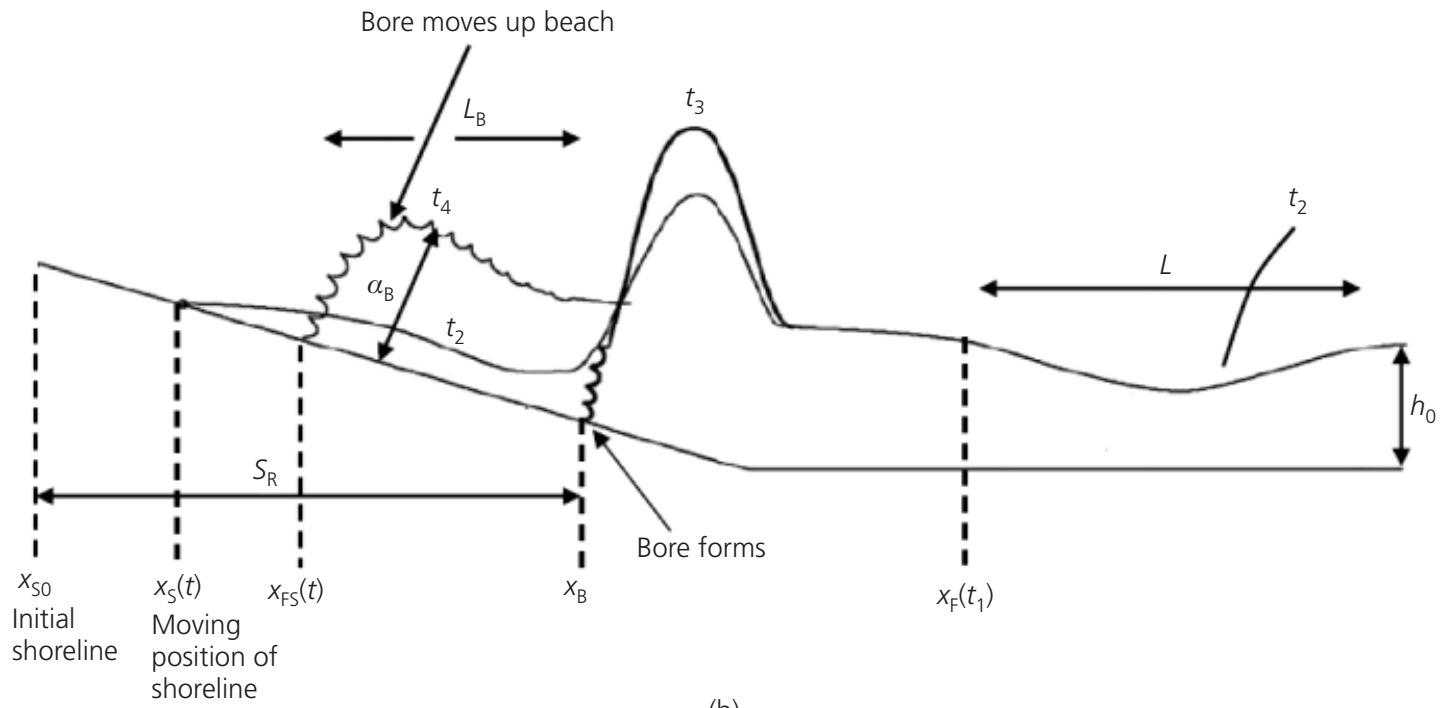

(b)

Figure 1. Schematic illustration of the experimental set-up and notation used in the analysis and descriptions of the observed phenomena: (a) overview; (b) at different stages in the development of the breaking wave. The times correspond to: $t_{1}$, incident wave; $t_{2}$, on the slope receding shoreline; $t_{3}$, the wave breaking; $t_{4}$, the bore moving up the slope 
$\alpha_{\mathrm{b}}$ (see Figure 1(a)). The first model uses a long-wave approximation and kinematic analysis to understand waves. The second describes the resulting surge up the beach and is based on a ballistic description that has been widely applied for run-up (e.g. Peregrine and Williams, 2001). It is therefore useful to consider integral measures of waves such as the total energy or total impulse. In dissipative systems, energy is not globally conserved but impulse is conserved when bed friction is weak. Thus, in this paper, impulse is used as a measure of the wave action prior to its interaction with the beach.

\subsection{Kinematic model prior to breaking}

The typical water velocity below the wave is

$$
u_{0} \approx \frac{a_{0}}{h_{0}} c
$$

where $c$ is the wave speed. Based on the continuity and Bernoulli's equations (Lamb, 1932), for $x>0$, the speed of the long waves varies slowly with the change in the elevation of the bottom surface $z_{\mathrm{s}}(x)$ according to

$$
\text { 1. } c=[g h(x)]^{1 / 2}\left[1 \pm \frac{1}{2} \frac{a(x, t)}{h(x)}\right]
$$

where

$$
h(x)=h_{0}-z_{\mathrm{s}}(x)
$$

with $z_{\mathrm{S}}=0$ for $x \leqslant 0, \boldsymbol{g}$ is the acceleration due to gravity, negative/positive signs correspond to depressed/elevated waves and $a(x, t)$ is the wave amplitude. The change in wave speed $\Delta c$ at a distance $x$ in the shoreward direction over the bottom slope is

2. $\Delta c \cong \frac{1}{2}\left[ \pm a(x, t)-\alpha_{\mathrm{b}} x\right]\left(\boldsymbol{g} / h_{0}\right)^{1 / 2}$

where $\alpha_{\mathrm{b}}=\mathrm{d} z_{\mathrm{s}} / \mathrm{d} x>0$. These equations are applied to the observed form of depression/elevation waves, whose surface has a uniform slope $\pm \alpha_{\mathrm{w}}(t)$ over the leading part of the wave, where $\alpha_{\mathrm{w}}$ varies with time $t$ (Figure 1(a)). Consider $a(x, t)$ between the front of the wave $x=x_{\mathrm{F}}$ and downstream of the maximum depression/elevation at $x_{\max }$, so that

$$
\text { 3. } a(x, t)= \pm\left|\alpha_{\mathrm{w}}\right|\left(x_{\mathrm{F}}-x\right)
$$

where $x_{\mathrm{F}}>x>x_{\max }$. Thence, by kinematic analysis of this timevarying sloping surface

$$
\begin{aligned}
-\frac{\mathrm{d}\left|\alpha_{\mathrm{w}}\right|}{\mathrm{d} t} & =\frac{\Delta c\left(x_{\mathrm{F}}\right)-\Delta c(x)}{x_{\mathrm{F}}-x} \\
& \cong \frac{1}{2}\left( \pm\left|\alpha_{\mathrm{W}}\right|-\alpha_{\mathrm{b}}\right)\left(\boldsymbol{g} / h_{0}\right)^{1 / 2}
\end{aligned}
$$

For such waves, the leading slope of the wave surface tends to decrease or increase until the surface slope is approximately equal to the beach slope. However, on the trailing V-shaped slope of the wave, where $x<x_{\max }$ and $\alpha_{\mathrm{w}}<0$, the wave slope $\left|\alpha_{\mathrm{w}}\right|$ tends to increase according to Equation 4. This shows why the general shape of the leading part of the depression varies slowly whereas, for the $\Lambda$ elevation part of the wave, the surface becomes steeper irrespective of the magnitudes of $\alpha_{\mathrm{w}}$ and $\alpha_{\mathrm{b}}$. This simplified hydraulic theory also shows why, when $\left|\alpha_{\mathrm{w}}\right| \approx \alpha_{\mathrm{b}}$, the overall length $L$ of the wave (e.g. a depressed triangular form) decreases, as given by

5. $\frac{\mathrm{d} L}{\mathrm{~d} t} \approx-\frac{1}{2}\left|\alpha_{\mathrm{w}}\right| L\left(\mathrm{~g} / h_{0}\right)^{1 / 2}$

As a consequence, the wavelength decreases dramatically as the wave moves into much shallower waters.

\subsection{Impulse considerations}

To estimate the non-linear development of the wave, consider the 'kinematic' impulse of an incident isolated wave (per unit width for a two-dimensional wave), defined as

$$
I_{0}=\int u \mathrm{~d} A
$$

where $A$ is taken over the whole water body (e.g. Eames and McIntyre, 1999; Stepanyants and Fabrikant, 1989). This is equal to the time integral of a horizontal force applied to the water body (per unit mass) that initiates a wave in the $x$-direction. The overall initial (kinematic) impulse of the wave can be written as

$$
I_{0}=C_{\mathrm{m}} a L c
$$

where $C_{\mathrm{m}}$ is the effective added mass coefficient and $c, a$ and $L$ are its speed, amplitude and wavelength respectively; $C_{\mathrm{m}} \sim 1$ for long waves in shallow waters while $C_{\mathrm{m}} \sim a / L$ for small-amplitude waves in deep water. For instance, long-wave analysis shows that $C_{\mathrm{m}}=1$ for solitary waves (Longuet-Higgins, 1974). Since the impulse is nearly constant, from Equations 2 and 5, the wave speed and length decrease and the amplitude $a(t)$ must increase. As the amplitude increases, however, the dynamics and the slope of the surface change because of significant non-hydrostatic forces in the wave (Klettner et al., 2010). When waves hit an obstruction, some of the wave energy is reflected. Similarly, when 
the wave breaks on a sloping beach, its velocity and pressure distributions are changed (Peregrine, 1983). In either case, some of the momentum of the wave is reflected, so that the impulse $I$ of the wave is reduced as $I=\lambda I_{0}$ (Taira and Nagata, 1968) where $\lambda \approx \lambda_{+}$for elevated waves and $\lambda \approx \lambda_{-}$for depressed waves. For an intensely breaking elevated wave, $\lambda_{+}<0 \cdot 5$. But for very long waves, as considered here, the unsteady reflection mechanism is weak, so $\lambda \approx 1$. Note that as the wave travels up the slope the impulse $I(t)$ is reduced weakly by the reactive forces of the slope and strongly by submerged obstructions (Fernando et al., 2008b). For unobstructed beaches this correction does not affect the results.

\subsection{Dynamic model post-breaking}

Consider a long depression in a sea surface of amplitude $a^{(-)}$, which is much less than the water depth $h_{0}$. The depression moves as a wave on the timescale $L_{\mathrm{c}} \sim 1 /\left(\mathrm{g} / h_{0}\right)^{1 / 2}$ (see Figure 1(a)). However, on the longer (non-linear) timescale over which the wave evolves (i.e. $L / \Delta u$ ), the water flows horizontally into the lower pressure below the depression with a velocity $\Delta u$, given by

6. $\Delta u \approx\left[g a^{(-)}\right]^{1 / 2}$

This backflow induces the shoreline to move down the beach from its initial position at $x=x_{\mathrm{S} 0}$ at a speed of the order of $\Delta u_{\mathrm{s}}$, which is comparable to $c$ when $a^{(-)}$is greater than about half the water depth $h(x)$. The moving shoreline, now at $x_{\mathrm{S}}(t)$, recedes over a draw-down distance

7. $S_{\mathrm{R}}^{(-)}=\beta_{\mathrm{S}}\left[a^{(-)} L / \alpha_{\mathrm{b}}\right]^{1 / 2}$

in order to fill up the depression wave (assuming $\alpha_{\mathrm{b}}$ is small), where $\beta_{\mathrm{S}}$ is a factor of the order unity, which depends on the wave shape. The receding flow meets the oncoming wave, which increases the steepness of its forward-sloping face. This first transforms into a collapsing breaker and then into a gravity current (or surge). Its movement towards the shore starts at the breaker point $x=x_{\mathrm{B}}$ at time $t_{\mathrm{B}}$, where $x_{\mathrm{B}} \sim x_{\mathrm{S} 0}-S_{\mathrm{R}}$ (Figure 1(b)). The initial length of the surge is $L_{\mathrm{B}}<L_{0}$, its amplitude is $a_{\mathrm{B}}$ and it moves with a velocity $u_{\mathrm{B}} \sim\left(\mathrm{g} a_{\mathrm{B}}\right)^{1 / 2}$.

By contrast, elevated waves, which do not generate a significant backflow $\left(S_{\mathrm{R}}^{(+)} \sim a_{\mathrm{B}}\right)$, recede over a limited distance and break on the beach close to the shoreline, where $x=x_{\mathrm{S}}$, as shown in Figure 2(b). The impulse of the breaking wave $I_{\mathrm{B}}$ is approximately determined by its initial height $a_{\mathrm{B}}$ and length $L_{\mathrm{B}}$ at time $t_{\mathrm{B}}$ so that

\section{8. $I_{\mathrm{B}}=L_{\mathrm{B}} a_{\mathrm{B}}\left(\boldsymbol{g} a_{\mathrm{B}}\right)^{1 / 2}=\left(\lambda_{-}, \lambda_{+}\right) I_{0}$}

where the coefficients apply to depressed and elevated waves respectively. Physical arguments and observations of bores sug- gest that $a_{\mathrm{B}}$ is of the order of $0 \cdot 25 L_{\mathrm{B}}$ for elevated and depressed waves (e.g. Figure 3). Therefore the initial bore amplitude is related to the impulse $I_{\mathrm{B}}$ by

9. $\quad a_{\mathrm{B}} \sim 0 \cdot 25 L_{\mathrm{B}}\left(t_{\mathrm{B}}\right) \sim 0 \cdot 5 I_{\mathrm{B}}^{2 / 5} \mathrm{~g}^{-1 / 5}$

Hence the surge velocity is related to $I_{\mathrm{B}}$ by

10. $u_{\mathrm{B}} \sim 0 \cdot 7 I_{\mathrm{B}}^{1 / 5} \mathbf{g}^{2 / 5}$

The length of the surge is approximately equal to the distance between the front of the surge $x_{\mathrm{FS}}$ and the wave breaking point $x_{\mathrm{B}}$. Thus, $L_{\mathrm{B}} \sim x_{\mathrm{FS}}-x_{\mathrm{B}}$ increases with time. However, the component of gravity along the slope slows down the surge according to

$$
\begin{aligned}
\frac{\mathrm{d} I_{\mathrm{B}}}{\mathrm{d} x} & \approx-\frac{\boldsymbol{g} \alpha_{\mathrm{B}}\left(a_{\mathrm{B}} L_{\mathrm{B}}\right)}{u_{\mathrm{B}}} \\
\text { 11. } & \approx-\boldsymbol{g}^{1 / 3} \alpha_{\mathrm{b}} I_{\mathrm{B}}^{1 / 3}\left(x_{\mathrm{FS}}-x_{\mathrm{B}}\right)^{2 / 3}
\end{aligned}
$$

The calculated 'run-up' distance $B_{\mathrm{R}}$ between $x_{\mathrm{B}}$ and where the surge stops (and $I_{\mathrm{B}}=0$ ) is given by

12. $B_{\mathrm{R}}=\beta_{\mathrm{R}}\left(\lambda_{-}^{2 / 5}, \lambda_{+}^{2 / 5}\right) \approx B_{\mathrm{R} 0}$

where

$$
B_{\mathrm{R} 0}=\frac{I_{0}^{2 / 5} \boldsymbol{g}^{-1 / 5}}{\alpha_{\mathrm{b}}^{3 / 5}}
$$

and $\beta_{\mathrm{R}}$ is a constant. A ballistic analysis would obtain the same dependence of $B_{\mathrm{R} 0}$ on $I_{0}$ and $\boldsymbol{g}$, because the change in wave shape would not then be taken into account. A ballistic analysis would lead to a stronger dependence on beach slope (i.e. proportional to $\alpha_{\mathrm{b}}^{-1}$ ). Dimensional analysis could be used to estimate Equations 10 and 12 , but would not predict the dependence on beach slope or other details of the above analysis. The distance to the run-up point from the initial shoreline is (for both types of wave)

13. $\Delta B_{\mathrm{R}}=B_{\mathrm{R}}-S_{\mathrm{R}}$

The relative net run-up distances for elevated/depressed waves is given by 
Draw-down and run-up of tsunami waves

on sloping beaches

Klettner, Balasubramanian, Hunt et al.
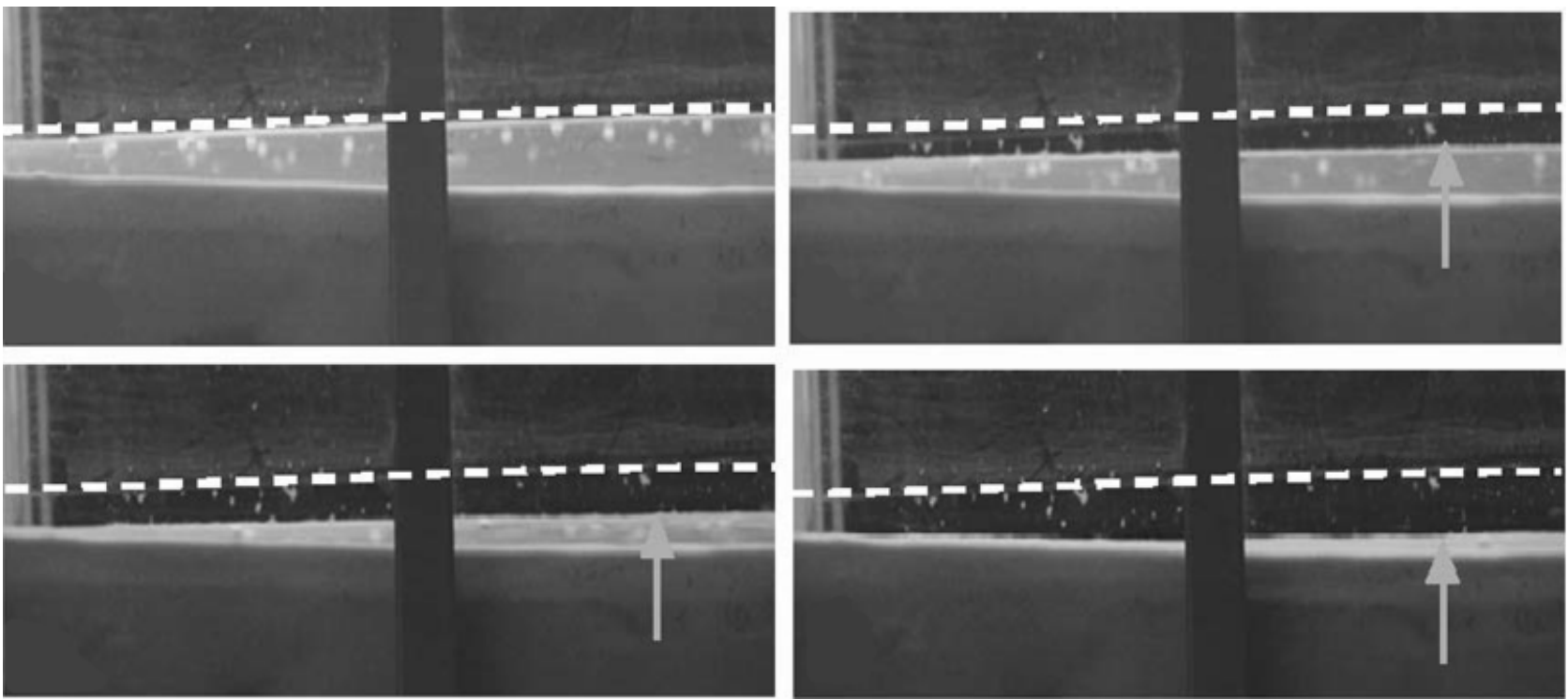

(a)
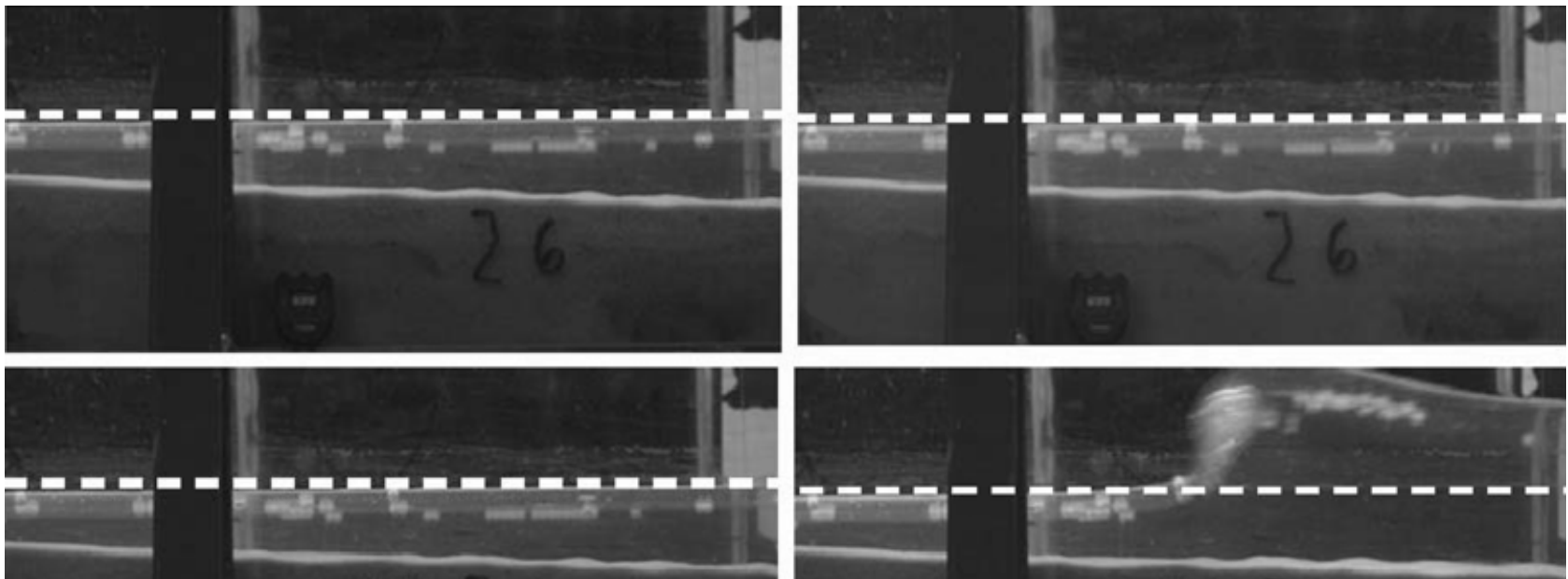

(b)

Figure 2. Photographs showing (a) recession due to a leading depression wave on the beach and (b) no or very little recession for a leading elevation wave on the beach. The white dotted lines denote the undisturbed water level and the arrows indicate current water level. The time difference between images is $1.2 \mathrm{~s}$

14. $\frac{\Delta B_{\mathrm{R}}^{(+)}}{\Delta B_{\mathrm{R}}^{(-)}}=\frac{\lambda_{+}^{2 / 5}-a_{\mathrm{B}}}{\lambda_{-}^{2 / 5}-S_{\mathrm{R}} / B_{\mathrm{R} 0}}$

Figure 4 shows the prediction of $B_{\mathrm{R}}$ with varying $I_{\mathrm{B}}$.

\section{Experimental study}

To test the concepts and provide quantitative validation of the model, a series of laboratory experiments was undertaken (Table 1).

\subsection{Experimental set-up}

The experiments were carried out in a $32 \times 0.8 \times 1.8 \mathrm{~m}$ wave tank at Arizona State University, as described in detail by Voropayev et al. (2003). The waves first propagate a distance of $3 \mathrm{~m}$ over the flat horizontal bottom of the tank in a constant water depth $h_{0}=0.8 \mathrm{~m}$. They then travel over a beach of slope $\alpha_{\mathrm{b}}=0 \cdot 04$. A novel technique was needed to generate a depression wave because if the wavemaker paddle is moved backwards through a displacement $\varepsilon$, the leading depression wave is overtaken by an elevated wave that destroys the depression wave. To suppress this trailing elevation wave, the design was modified; a 


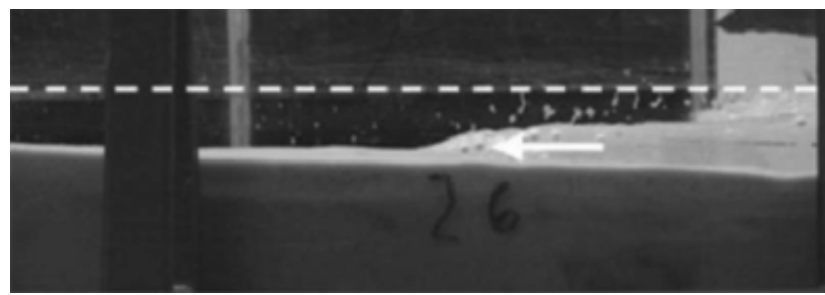

(a)

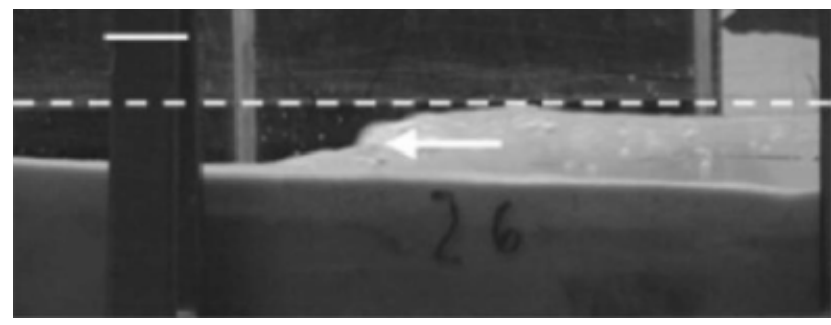

(b)

Figure 3. Photographs showing the propagation of a surge (white arrow) for the leading depression wave. The dimensionless wave amplitude $a^{(-)} / h_{0}=0.081$. The white dotted line denotes the undisturbed water level. The solid white line represents $0.5 \mathrm{~m}$ length. The time difference between images is $1.5 \mathrm{~s}$

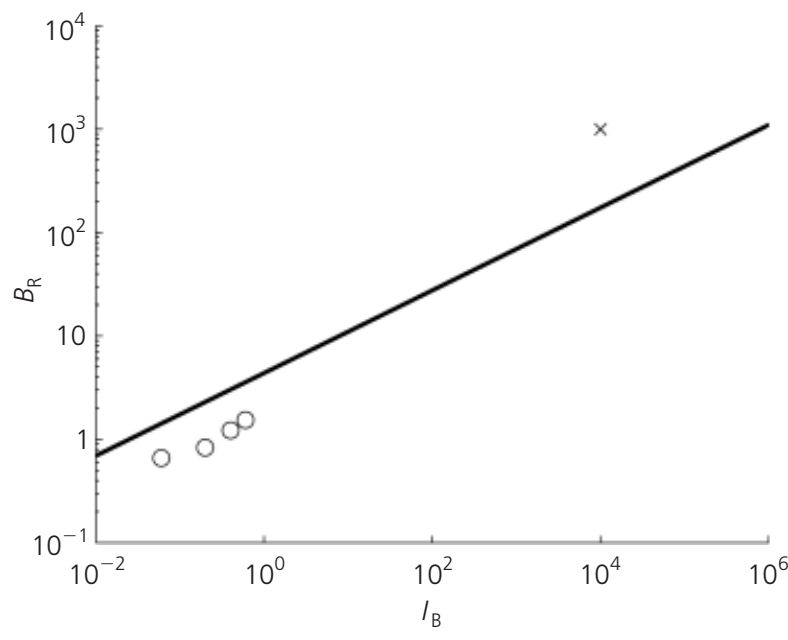

Figure 4. Prediction of beach run-up according to Equation 12 with $\beta_{\mathrm{R}}=1$ and $\beta_{\mathrm{S}}=1$. Experimental data for depressed waves $(\circ)$ and field observation $(X)$ from the Indian Ocean tsunami are also shown

$\begin{array}{lllll}\text { Paddle displacement } \varepsilon: m & 0.10 & 0.20 & 0.30 & 0.40 \\ \text { Maximum run-up } \Delta B_{\mathrm{R}}^{(-)}: \mathrm{m} & 0.22 & 0.29 & 0.42 & 0.55 \\ \text { Maximum recession } S_{\mathrm{R}}^{(-)}: \mathrm{m} & 0.44 & 0.54 & 0.80 & 0.99 \\ \text { Maximum run-up } \Delta B_{\mathrm{R}}^{(+)}: \mathrm{m} & 0.55 & 0.79 & 1.15 & 1.50\end{array}$

Table 1. Summary of the wave tank experiments for depression/ elevation waves 'leaky' hinged plate $(1.7 \mathrm{~m}$ high, $0.79 \mathrm{~m}$ wide and $0.0254 \mathrm{~m}$ thick) was introduced $2 \mathrm{~m}$ from the paddle, with a gap of $0.005 \mathrm{~m}$ between the paddle and the tank walls, see Figure 1(a).

As the driving paddle forms a depression, the hinged plate rotates backwards by $\sim 30^{\circ}$ as the depression wave passes below and either side of the plate. The paddle does not affect this slow process. However, when the trailing elevated wave arrives, the paddle resists its motion. Through trial and error, in the final design the initial elevation amplitude was reduced to about a quarter of the depression amplitude, depending on the amplitude of the wave (see Figure 5). The measured $\mathrm{V}-\Lambda$ wave profile resembles the leading part of the depression wave observed in the 2004 Sumatra tsunami off Thailand (as evident from tidal gauge records (Raveloson et al., 2008)) and discussed theoretically by Carrier et al. (2003). A similar profile was measured by a tidal gauge in Japan north of Sendai, where extended drawdown occurred in 2011. With the plate in place, the depression wave breaks $15 \mathrm{~m}$ from the paddle over the flat sandy slope. Here, $\varepsilon=0 \cdot 1,0 \cdot 2,0 \cdot 3$ and $0.4 \mathrm{~m}$. The paddle displacement $X$ is sinusoidal $(X=0.5 \varepsilon \sin t$ where $\pi / 2 \leqslant t \geqslant 3 \pi / 2)$ so that the paddle starts and ends with zero velocity with a time period of $T=2.5 \mathrm{~s}$. Each experiment was repeated 15 times with an accuracy of $5 \%$ for the amplitude of the depression wave. Standard acoustic Doppler velocimetry and wave gauge measurements were carried out at selected sections to obtain velocities and wave amplitude profiles. The uncertainties in the measurements were: wave amplitude $a \pm 0.005 \mathrm{~m}$, initial amplitude of surge $a_{\mathrm{B}} \pm 0.01 \mathrm{~m}$, velocity of surge $u_{\mathrm{B}} \pm 0 \cdot 1 \mathrm{~m} / \mathrm{s}$, maximum run-up $\Delta B_{\mathrm{R}} \pm 0.02 \mathrm{~m}$, shoreline recession $S_{\mathrm{R}} \pm 0.02 \mathrm{~m}$ and maximum velocity of shoreline recession $\Delta u_{\mathrm{s}} \pm 0 \cdot 2 \mathrm{~m} / \mathrm{s}$.

\subsection{Experimental results}

Time series of the free surface elevation $h(t)$ were taken at specific measurement points $x_{\mathrm{m}}$ from the wavemaker along the tank and were converted into height-distance $h\left(x-x_{\mathrm{F}}\right)$ profiles using the transformation $x=t(\boldsymbol{g} h)^{1 / 2}$. The measured streamwise profiles of wave height for $\varepsilon=0.2,0.3$ and $0.4 \mathrm{~m}$ are plotted in Figure 5 relative to the front of the wave (where $x=x_{\mathrm{F}}$ ) at different distances of the wave front from the wavemaker defined by $\left(x_{\mathrm{F}}+x_{\mathrm{w}}\right)$.

Figure 5 shows that the changes in peak depression amplitudes $a^{(-)}$on the sloping beach are small for large-amplitude waves and increase by less than $20 \%$ for small-amplitude waves $(\varepsilon=0.2 \mathrm{~m})$. However, the trailing elevation amplitudes $a^{(+)}$ always increase (by as much as a factor of 10) as the wave travels up the slope, until the trailing slope is nearly vertical at the crest.

Figure 6 shows the variation of the ratio $a^{(-)} / L$ with distance from the wavemaker $\left(x_{\mathrm{F}}+x_{\mathrm{W}}\right)$. These results confirm that the initial amplitude of the depression waves increased approximately linearly with the paddle displacement (i.e. $a^{(-)} / L \propto \varepsilon$ ). Note that, since the period of the paddle displacement was the same, for 


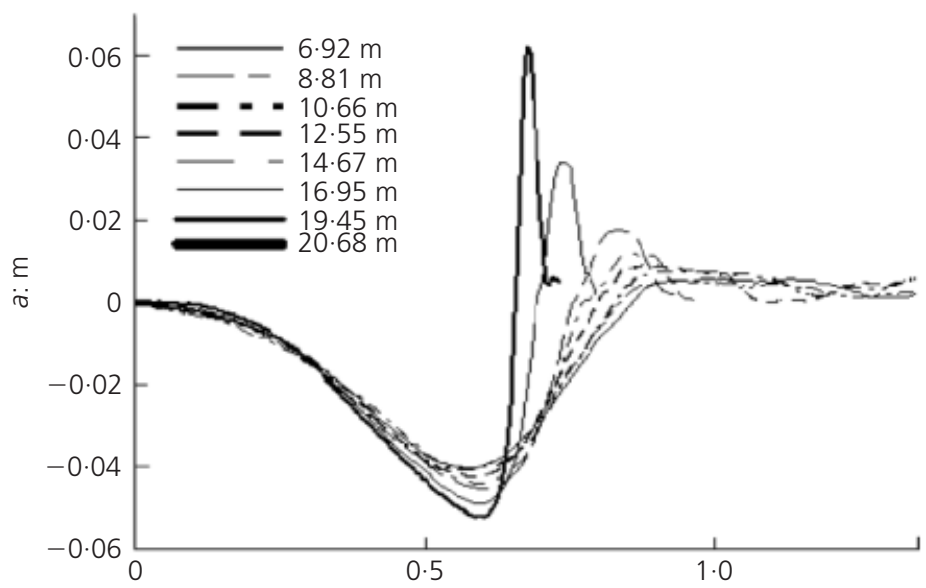

(a)
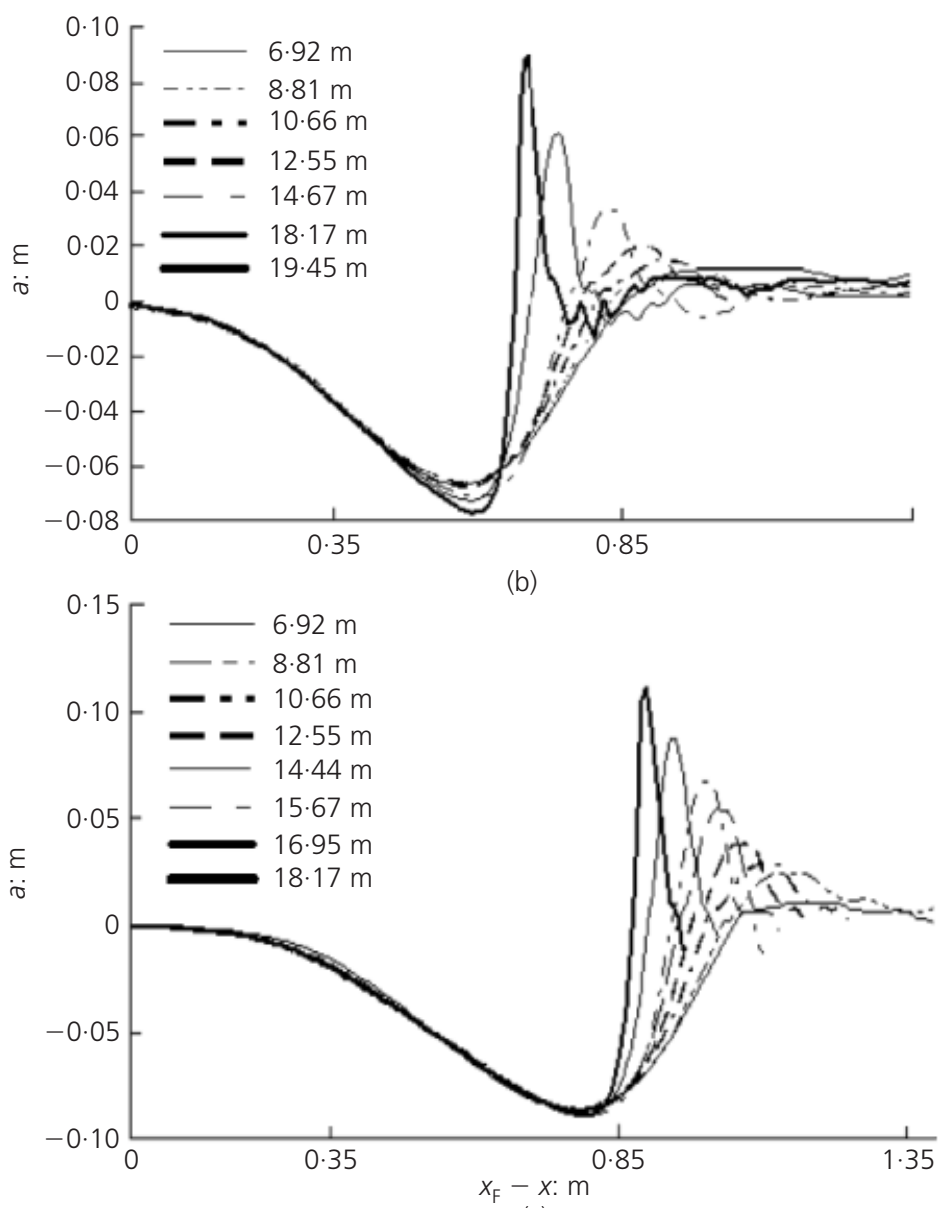

(c)

Figure 5. Wave amplitude over sloping bottom plotted as a function of distance $\left(x_{F}-x\right)$ from the front of the wave (where $\left.x=x_{\mathrm{F}}\right)$ at different distances from the wavemaker $\left(x_{\mathrm{F}}+x_{\mathrm{W}}\right)$ for a wavemaker stroke of (a) $\varepsilon=0.2 \mathrm{~m}$, (b) $\varepsilon=0.3 \mathrm{~m}$ and (c) $\varepsilon=0.4 \mathrm{~m}$

these long waves the wavelength $L(\approx 1.2 \mathrm{~m})$ did not vary significantly with amplitude. As the wave moves up the sloping beach, the amplitude and form of the wave varied non-linearly. The length of the wave decreased significantly, which is to be expected as the back of the wave is travelling faster than the front of the wave. The negative slope $\alpha_{\mathrm{w}}$ of the leading part of the wave $\left(a^{(-)} / L\right)$ was about three times greater than the slope of the beach for all three amplitudes considered. Figure 6 also shows 
Draw-down and run-up of tsunami waves

on sloping beaches

Klettner, Balasubramanian, Hunt et al.

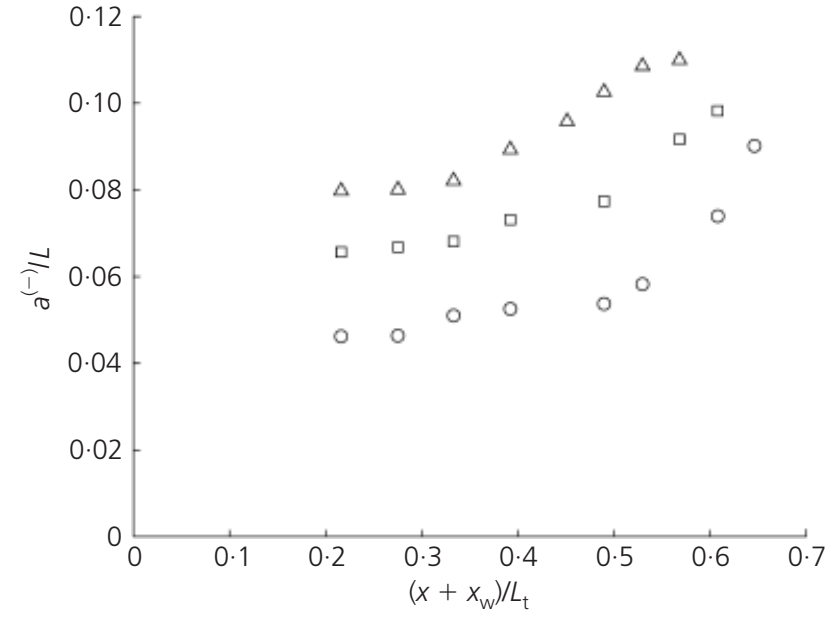

Figure 6. Variation of the peak depression amplitude, $a^{(-)}$(up to the point where the wave breaks) normalised by the wavelength $L$, with distance from the wavemaker $\left(x+x_{w}\right)$, normalised by the wave tank length $\left(L_{\mathrm{t}}\right)$ for $\varepsilon=0.2 \mathrm{~m}(0), \varepsilon=0.3 \mathrm{~m}(\square)$ and $\varepsilon=0.4 \mathrm{~m}(\triangle)$

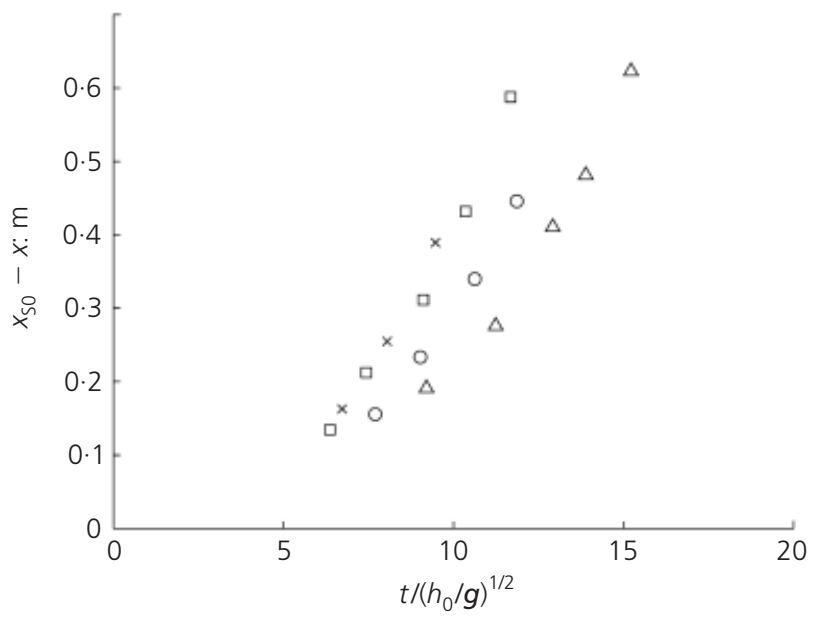

Figure 7. Recession of the shoreline $\left(x_{s}\right)$ from its initial position $x_{s 0}$ as a function of non-dimensional time from the initiation of the wave for depression waves with $\varepsilon=0.1 \mathrm{~m}(\times), \varepsilon=0.2 \mathrm{~m}(\mathrm{O})$, $\varepsilon=0.3 \mathrm{~m}(\square)$ and $\varepsilon=0.4 \mathrm{~m}(\triangle)$

that, for the smallest wave amplitude, the magnitude of the depression $a^{(-)}$increases more sharply towards its point of breaking.

Figure 7 shows the shoreline recession $x_{\mathrm{s}}$ as a function of time. As the wave moves up the slope the amount of recession is greater with increased wave amplitude; the velocity of the recession is not dependent on the amplitude of the wave. Figure 2 shows two time sequences of the change in water height $h(x, t)$ relative to its initial level. The water was seeded with tracer elements to assist with visualisation of the movement of the body

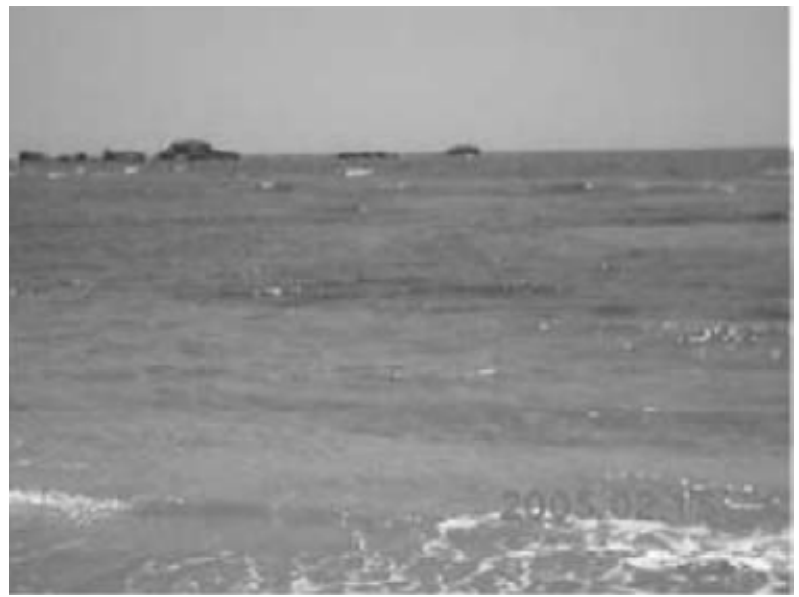

(a)

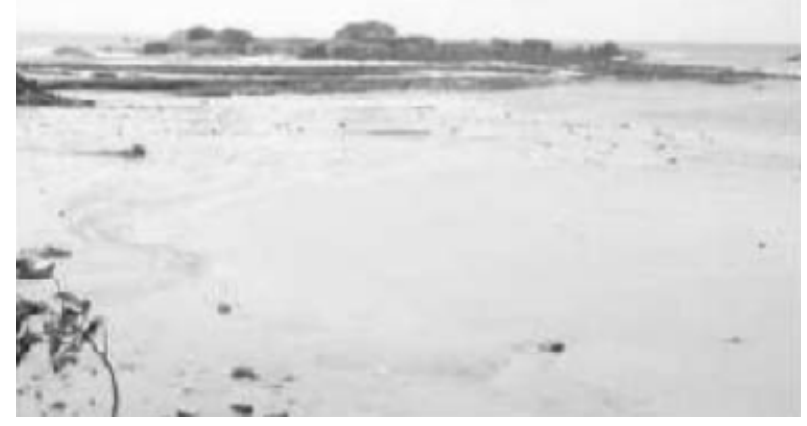

(b)

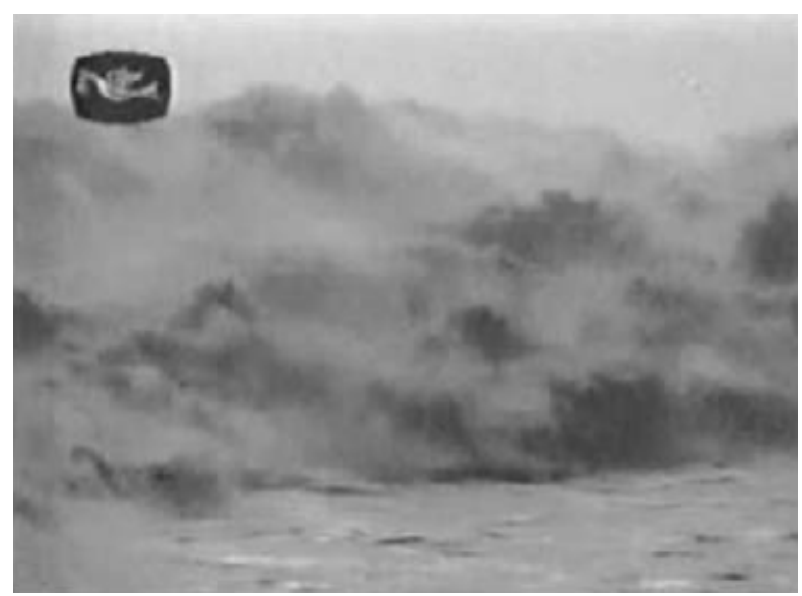

(c)

Figure 8. (a) Usual appearance of ocean rock reef from the west coast town of Hikkaduwa, Sri Lanka. (b) Appearance from approximately the same location about 20 min prior to the arrival of the Sumatra tsunami on 26 December 2004; there was a drawdown of about $0.5 \mathrm{~km}$ (photo courtesy of Mr Mambo Thushara).

(c) Arrival of the tsunami in the area, videotaped by a local resident (courtesy Rupavahini, Sri Lanka) 
of water. Figure 2(a) shows that the shoreline recedes substantially until it meets the forward motion of the trailing elevation wave, forcing the elevated wave upwards. The amplifying trailing slope soon breaks, forming a collapsing front having the appearance of a hydraulic bore, as seen in many photographs of tsunamis (see Figure 8). Figure 3 shows how the surge has a well-defined two-layer structure in which a well-defined bore rides over the receded layer of water below it. After some time, however, the bore overtakes the receding shoreline and propagates up the dry beach slope, as is commonly observed in gravity currents (Carrier et al., 2003). By contrast, Figure 2(b) shows how, for elevated waves of similar initial amplitude, there is negligible recession of the shoreline and the amplified wave plunges onto the shore. As noted above, the maximum velocity of the recession appears to be insensitive to the wave amplitude $a^{(-)}$, so it is likely to depend primarily on the depth $h_{0}$ and beach slope $\alpha_{\mathrm{b}}$. The maximum length of the recession $S_{\mathrm{R}}$ increases with $a^{(-)}$as expected from Equation 7. This may be associated with the receding flow raising the maximum elevation of the overturning wave.

\section{Comparison of experiments, model predictions and observations}

The results of the laboratory experiments are consistent with the proposed simplified hydraulic model. They show why depressed tsunami waves exhibit a similar $\mathrm{V}-\Lambda$ behaviour on most beaches with low slopes causing the shoreline recession, followed by significant surge onshore in the form of a collapsing gravity current. The behaviour is similar because the leading wave slope tends to the gradient of the beach. The effects of wave dynamics on the final run-up may not be as significant as suggested in most previous studies, but they certainly control the initial backwash.

The model enabled the laboratory experiments to be extrapolated to geophysical-scale flows and for comparisons to be made with field observations. Figure 4 shows the comparison of the model with the experimental results. For the experiments, $\alpha_{\mathrm{b}}=0.04$, $c \sim\left(g h_{0}\right)^{1 / 2} \sim 3 \mathrm{~m} / \mathrm{s}, L \sim 1 \mathrm{~m}$ and the amplitude $a^{(-)}$varied from $\sim 0.02 \mathrm{~m}$ to $0.1 \mathrm{~m}$. This gave $I_{0}$ ranging from $\sim 0.06$ to $\sim 0.3 \mathrm{~m}^{3} / \mathrm{s}$ from the smallest to the largest wave respectively. The model predicts greater values of $B_{\mathrm{R}}$ and $u_{\mathrm{B}}$ than observed in the experiments. This could be because the model does not take into account breaking, which is an extremely turbulent process that dissipates a lot of energy. Also, the model does not take into account friction effects that would slow the bore down and therefore decrease $B_{\mathrm{R}}$.

For comparison, elevated waves were also simulated in the tank with the same wavemaker displacement $\varepsilon$. The hinged paddle was removed for these experiments. The beach run-up length $\Delta B_{\mathrm{R}}^{(+)}$ was about three times that of the leading depression wave (see Figure 2(b) and Table 1). This increase is consistent with the estimate from Equation 14, which gives factors of between 2 and 4 for the smallest to the largest amplitudes. Therefore, laboratory experiments are broadly consistent with the trends and approximately consistent with the model predictions.

The most detailed field data of an approaching tsunami were taken on the yacht Mercator, located $1.6 \mathrm{~km}$ off the coast of Phuket, Thailand, on 26 December 2004 (Grilli et al., 2007). As expected for a long wave in a depth of $13 \mathrm{~m}$, the waves showed a classical $\mathrm{V}-\Lambda$ shape, or reflected $\mathrm{N}$ shape; this was also observed by shore-based tide gauges (Raveloson et al., 2008). In deeper water, the tsunami probably had a form more like that considered in this study, as proposed in Carrier et al. (2003), with $a^{(-)} /$ $a^{(+)} \approx 5$. As the wave travelled onshore, the trailing elevation would have been increasing in amplitude. Full-scale tsunamis vary greatly in their (kinematic) impulse (per unit width), typically from $10^{3}$ to $10^{7} \mathrm{~m}^{3} / \mathrm{s}$, which could correspond to the range that might be produced by bottom slumping downslopes of $100 \mathrm{~km}$ at the continental shelf following earthquakes (Hunt, 2005).

The experiments and observational data for the Sumatra tsunami when it reached Sri Lanka also showed a recession of the shoreline before the final arrival of the tsunami front (Figures $8(\mathrm{a})$ and $8(\mathrm{~b})$ ). The front had the form of a collapsing bore, similar to the laboratory experiments shown in Figure 3. Near the shore, the impulse is reduced by reflection and diffraction (e.g. offshore Thailand), $c \sim 10 \mathrm{~m} / \mathrm{s}, a^{(-)} \sim 1 \mathrm{~m}, L \sim 1 \mathrm{~km}$, so that $I_{0} \sim 10^{4} \mathrm{~m}^{3} / \mathrm{s}$ (the beach slope was $\sim 0 \cdot 04$ ). Quantitative estimates from the model can be derived for this case where, in the approaching wave, $a^{(-)} \approx 1 \mathrm{~m}, L \approx 50 \mathrm{~km}$ and the beach slope $\alpha_{\mathrm{b}} \approx 0.04$; the predicted values are $u_{\mathrm{B}} \sim 15 \mathrm{~m} / \mathrm{s}, a_{\mathrm{B}} \sim 20 \mathrm{~m}$, $S_{\mathrm{R}} \sim 800 \mathrm{~m}, B_{\mathrm{R}} \sim 1000 \mathrm{~m}$, so that $\Delta B_{\mathrm{R}} \sim 200 \mathrm{~m}$ (assuming that the beach slope does not decrease). In fact, as shown in Figure $8(\mathrm{~b})$, the observed value of the draw-down distance $S_{\mathrm{R}}^{(-)}$was about $0.6 \mathrm{~km}$; because the beach flattened out, the surge travelled up to $2 \mathrm{~km}$ inland (Liu et al., 2005). This explains why the model underpredicts the run-up distance compared with the observations in Figure 2(a). The magnitude of the velocity of the bore $u_{\mathrm{B}}$ is consistent with that estimated by Shuto and Matsutomi (1995) for the large Hokkaido Nansei-Oki tsunami, which appears to have had similar hydrodynamic parameters; they concluded that the overland flow velocity of the surge $u_{\mathrm{B}}$ was $10-18 \mathrm{~m} / \mathrm{s}$.

\section{Discussion}

Previous computational and theoretical studies of non-breaking waves impacting on beaches (Carrier et al., 2003; Guus Stelling, personal communication) have reported that $\mathrm{V}-\Lambda$-shaped waves have a longer run-up than those where the slope faces upstream (i.e. with a $\Lambda-\mathrm{V}$ shape). However, many elevated tsunami waves are in the form of shorter timescale wave trains where there is significant reflection and $\lambda_{+} \sim 1$ (Fernando et al., 2008a). In that case, $\Delta B_{\mathrm{R}}^{(+)}$can be less than $\Delta B_{\mathrm{R}}^{(-)}$. On most coastlines, beaches become flat, which is why surges can move further inland than indicated by Equation 13, causing widespread damage. However, idealised models do not allow for the waves to steepen and break before reaching the beach, which causes significant reflection. 
These are both important processes in the experiments and the modelling approach presented in this paper.

It should also be noted that the experimental and theoretical predictions are consistent with the work of Tadepalli and Synolakis (1994) who used the first-order shallow-water equations to show that, for generalised $\mathrm{N}$-waves (where there is a leading depressed component with a trailing elevated component), run-up was further than for solitary waves with the same positive maximum amplitude and wave steepness $\left(R_{\mathrm{N}} / R_{\mathrm{sol}}=1 \cdot 46\right)$. However, if waves of equal potential energy are considered, it can be shown that the run-up of the solitary wave is greater $\left(R_{\mathrm{N}} / R_{\text {sol }}=0 \cdot 83\right)$. This shows that comparisons of the run-up of waves should be based on momentum or energy, not just wave amplitude or wave steepness. A depression wave slows down before breaking as the V-wave deepens; the trailing slope of the trailing $(\Lambda)$ part of the wave increases and the overall wavelength decreases; the momentum flux thus increases as the wave passes and so consequent damage to structures increases. After breaking, the original impulse of the wave decreases as the surge moves up the beach (as seen in Figure 3). Any submerged obstructions in the flow (e.g. coral reefs) would also impede the flow and thus reduce possible damage as they remove momentum in the flow (Fernando et al., 2008b). As global warming is predicted to raise sea levels by $\Delta h$ (which maybe as high as $0.6 \mathrm{~m}$ by 2100 , particularly in warmer equatorial regions (IPCC, 2007)), the distance that the surge travels $S_{\mathrm{R}}^{(-)}$up the beach is expected to increase (by the order of $\Delta h / \alpha_{\mathrm{b}} \sim 30 \mathrm{~m}$ ). This increases the probability of wave surges moving inland over low-lying coastal areas (www.geology.com/news). In developing countries, with much non-resilient housing, this could have devastating results (Rossetto et al., 2007). Furthermore, as global warming reduces the ice sheet in Arctic waters, a continuing and significant level of seismic activity in the area could in future lead to the generation of tsunamis, which are currently damped by ice cover. An important recommendation of this study is to make greater use of the recently installed early warning systems (e.g. Lauterjung, 2007) that are based on measurements of pressure fluctuations at the seabed. Improved understanding of tsunami hydrodynamics is considered to be a key for such refinements (Synolakis and Bernard, 2006).

Using the characteristics of the depression/elevation waves derived in this paper, the forms of tsunami waves on beaches could be predicted more accurately and in real time. Local conditions such as coastal bathymetry and beach slope would have to be taken into account to improve estimated results. These expressions should only be used as guidelines as they do not take into consideration factors such as the merging of edge waves, which tend to produce greater run-up than two-dimensional waves (Day et al., 2005). Therefore, warnings to the public and relevant agencies could be more detailed about the likely behaviour of tsunamis on beaches and how far they might move inland.

\section{Conclusions}

A weakly non-linear hydraulic model has been presented. Application of the model, based on the conservation of impulse, to the late stages of a shoaling elevated or depressed wave explains quantitatively how such waves behave before and after breaking. The model relates the significant quantities to be included in warnings (e.g. draw-down, run-up and surge velocity) to the initial geophysical forcing causing a tsunami.

Using a novel wavemaker to generate depressed waves, laboratory experiments were carried out to validate the proposed hydraulic model; experimental data and model predictions were found to be consistent. The model predictions were also consistent with video footage of full-scale tsunamis. Over a sloping bottom, shortening and steepening of the depression wave preceded a rapidly growing elevation, forming a $\mathrm{V}-\Lambda$-wave, as observed at tidal stations in the Pacific. This causes the shoreline to recede until it is entrained into the trailing $\Lambda$-wave, which, as it breaks, transforms into an energetic gravity current moving up the beach and then inland, as in the Indian Ocean and Hokkaido tsunamis. The run-up distance for depressed waves in the laboratory study was found to be less than that for elevated waves - a result that differs from theories of non-breaking waves.

\section{Acknowledgements}

The authors are grateful to Prof. Guus Stelling, Prof. P. L. F. Liu, the late Prof. Howell Peregrine and Dr Simon Day for discussions about tsunami waves, and to Leonard Montenegro and Dave Gillespie for assistance with the experimental design. Christian Klettner acknowledges financial support from the Engineering and Physical Sciences Research Council (EPSRC) and a grant from Arizona State University (ASU). Coastal wave propagation research at ASU was funded by the Office of Naval Research.

\section{REFERENCES}

Carrier GF, Wu TT and Yeh H (2003) Tsunami run-up and drawdown on a plane beach. Journal of Fluid Mechanics 475: 79-99.

Day SJ, Watts P, Grilli ST and Kirby JT (2005) Mechanical models of the 1975 Kalapena, Hawaii Earthquake and Tsunami. Marine Geology 215(1-2): 59-92.

Eames I and McIntyre ME (1999) On the connection between Stokes and Darwin drift. Proceedings of the Cambridge Philosophical Society 126: 171-174.

Fernando HJS, Braun A, Galappatti R, Ruwanpura J and Wirisinghe SC (2008a) Tsunamis: manifestation and Aftermath. In Large Scale Disasters. Cambridge University Press, Cambridge, UK, pp. 258-292.

Fernando HJS, Samarawickrama SP, Balasbramanian S, Hettiarachchi SSL and Voropayev SI (2008b) Effects of porous barriers such as coral reefs on coastal reefs on coastal wave propagation. Journal of Hydroenvironmental Research 1(3-4): 187-194.

Grilli ST, loualalen M, Asavanaut J et al. (2007) Source constraints and model simulation of the December 26, 2004 Indian Ocean tsunami. Journal of Waterway, Port, Coastal and Ocean Engineering 133(6): 414-428. 
Hunt JCR (2005) Tsunami waves and coastal flooding. Mathematics Today October: 144-146.

IPCC (Intergovernmental Panel on Climate Change) (2007) Fourth Assessment Report. See http://www.ipcc.ch/ publications_and_data/ar4/wg1/en/ch10s10-6-5.html (accessed 10/12/2010).

Klettner CA, Eames I, Hunt JCR and Fernando HJS (2010) Evolution and run-up of tsunamis. In Progress in Industrial Mathematics at ECMI 2008 (Fitt AD, Norbury J, Ockenden H and Wilson E (eds)). Springer, Berlin, Germany, pp. 271-276.

Kobayashi N and Lawrence AR (2004) Cross-shore sediment transport under breaking solitary waves. Journal of Geophysical Research 109: C03047, http://dx.doi.org/ 10.1029/2003JC002084.

Lamb H (1932) Hydrodynamics. Cambridge University Press, Cambridge, UK.

Lauterjung J (2007) Status Quo of the Tsunami Early Warning System for the Indian Ocean. See http://www.physorg.com/ news117370656.html (accessed 10/12/2010).

Liu PLF, Lynett P, Fernando H et al. (2005) Observations by the international tsunami team in Sri Lanka. Science 308(5728): 1595.

Longuet-Higgins MS (1974) On the mass, momentum, energy and circulation of a solitary wave. Proceedings of the Royal Society of London A 337: 1-13.

Peregrine DH (1983) Breaking waves on beaches. Annual Review of Fluid Mechanics 15: 149-178.

Peregrine DH and Williams SM (2001) Swash overtopping a truncated beach. Journal of Fluid Mechanics 440: 391-399.
Raveloson R, Sodoudi F and Kind R (2008) Broadband seismometers are good tsunamimeters. Geophysical Research Abstracts 10: 06426

Rossetto T, Peiris N, Pomonis A et al. (2007) The Indian Ocean tsunami of December 26, 2004: observations in Sri Lanka and Thailand. Natural Hazards 42(1): 105-124.

Shuto N and Matsutomi H (1995) Field survey of the 1993 Hokkaido Nansei-Oki tsunami. Pure and Applied Geophysics 144(1-2): 649-663.

Soloviev SL and Mazova RK (1994) On the influence of sign of leading tsunami wave on runup height on the coast. Science of Tsunami Hazards 12(1): 25-31.

Stepanyants YA and Fabrikant AL (1989) Propagation of waves in hydrodynamic shear flows. Soviet Physics Uspekhi 32: 783-805.

Synolakis CE and Bernard EN (2006) Tsunami science before and beyond Boxing Day 2004. Philosophical Transactions of the Royal Society A: Mathematical, Physical \& Engineering Sciences 364(1845): 2231-2265.

Tadepalli S and Synolakis CE (1994) The runup of N-waves on sloping beaches. Proceedings of the Royal Society of London A 445(1923): 99-112.

Tadepalli S and Synolakis CE (1996) Model for the leading waves of tsunamis. Physical Review Letters 77(10): 2141-2144.

Taira K and Nagata Y (1968) Experimental study of wave reflection by a sloping beach. Journal of the Oceanographical Society of Japan. 24(5): 242-252.

Voropayev SI, Testik FY, Fernando HJS and Boyer DL (2003) Burial and scour around a short cylinder under progressive shoaling waves. Ocean Engineering 30(13): 1647-1667.

\section{WHAT DO YOU THINK?}

To discuss this paper, please email up to 500 words to the editor at journals@ice.org.uk. Your contribution will be forwarded to the author(s) for a reply and, if considered appropriate by the editorial panel, will be published as a discussion in a future issue of the journal.

Proceedings journals rely entirely on contributions sent in by civil engineering professionals, academics and students. Papers should be 2000-5000 words long (briefing papers should be 1000-2000 words long), with adequate illustrations and references. You can submit your paper online via www.icevirtuallibrary.com/content/journals, where you will also find detailed author guidelines. 